\title{
Asthma: Overview on Diagnostic and Management approach in Primary Health Care
}

\author{
Belal Sara Hassan $\mathbf{M}^{\mathbf{1}}$, Jaha Mohammad Jameel $\mathbf{M}^{\mathbf{1}}$, Alzahrani Majed Khidhran $\mathbf{M}^{1}$, Alyamani Amani Mohammad $\mathbf{A}^{1}$, Munshi Ameer \\ Hashim A ${ }^{1}$, Kalantan Aseal Abdulhamid I' , Sagr Abdulmajeed Adil M ${ }^{1}$, Noura Hussain Alhussaini ${ }^{2}$, Duaa Hashim Alsaleh ${ }^{3}$, Alzahrani \\ Majed Khidhran $\mathbf{M}^{1}$, Yasir Khalid Alghamdi ${ }^{4}$, Ahmed mansour Asiry ${ }^{2}$
}

${ }^{1}$ Department of Emergency, Heraa General Hospital, Makkah, KSA. ${ }^{2}$ Faculty of Medicine, Ibn Sina National College of Medicine, Jeddah, KSA. ${ }^{3}$ Department of Family Medicine, Primary Health Care, Khobar, KSA. ${ }^{4}$ Faculty of Medicine, King Abdulaziz University, Jeddah, KSA

\section{Abstract}

The clinical presentation of asthma and intensity of airway inflammation presents with heterogeneity. Asthma management aims to minimize the symptoms and risks of exacerbations to achieve control over the disease. Risk factors include smoking, obesity, occupational and environmental risk factors, and a genetic predisposition, among others. Asthma therapy aims to minimize the symptoms and risks of exacerbations to achieve control over the disease. Pharmacological treatment of asthma is based on an assessment and reevaluation cycle where symptoms, risk factors, comorbidities, and side effects are all examined. In this article, we aim to provide a summarized, yet comprehensive paper that discusses Asthma presentation in primary health care, and its diagnostic and management approach. The Medline, Pubmed, Embase, NCBI, and Cochrane databases were searched for studies of patients with asthma symptoms. Incidence, etiology, and management options were analyzed. Asthma is a complex and heterogenic disease originating from a multitude of gene-environment interactions. Most asthma presents type 2 inflammation, seen in allergic conditions. Asthma presents in episodes, with environmental triggers that tend to vary among asthmatics. Treatment does not cure the disease but rather the objective is to maintain control.

Keywords: Asthma, Respiratory disease, Allergens, Inhaled corticosteroids (ICS)

\section{INTRODUCTION}

One of the most common non-communicable diseases in adults and children that is characterized by airflow limitation and respiratory symptoms is asthma. Complex geneenvironment interactions, with heterogeneity, contribute to developing asthma that leads to clinical presentation and intensity of airway inflammation [1]. Asthma therapy aims to minimize the symptoms and risks of exacerbations to achieve control over the disease. Pharmacological treatment of asthma is based on an assessment and reevaluation cycle where symptoms, risk factors, comorbidities, and side effects are all examined. However, the mainstream treatments for asthma remain anti-inflammatory and bronchodilator treatments. Necessary therapy is recommended for Asthma to keep it under control due to high intensity and severity, or if it does not respond to treatment. Recently, phenotype-specific new opportunities for intercessions and the understanding of more personalized therapy are being uncovered with developments in biomarkers and new biological therapies for the treatment of severe asthma [1].

\section{REsults And Discussion}

The overall incidence of diagnosed asthma in adults is $4.3 \%$ (95\% CI 4.2-4.4), with a substantial geographical disparity, and 334 million people around the globe have asthma. The highest prevalence of asthma in developed countries such as
Australia is $(21.0 \%)$ [2], and lowest in developing countries such as China $(0 \cdot 2 \%)$ [2]. However, asthma symptoms in children have more geographical disparity, reaching from $2.8 \%$ (Indonesia) to $37.6 \%$ (Costa Rica) in children aged 67 years, and from $3.4 \%$ (Albania) to $31.2 \%$ (Isle of Man) in children aged 13-14 years [3]. However, poorer countries are very likely underestimating the prevalence of the disease, as patients may not have access to health care as easy and basic asthma medication may not be available. That being said, the prevalence of asthma seems to be increasing in developing countries as lifestyles become westernized and appears stable/decreasing in developed countries. These global patterns show the importance of environmental factors, as illustrated by studies [4] of the prevalence of asthma from

Address for correspondence: Belal Sara Hassan $M$, Department of Emergency, Heraa General Hospital, Makkah, KSA.

Dr.belalsara @ gmail.com

This is an open-access article distributed under the terms of the Creative Commons Attribution-Non Commercial-Share Alike 3.0 License, which allows others to remix, tweak, and build upon the work non commercially, as long as the author is credited and the new creations are licensed under the identical terms.

How to cite this article: Belal S H M, Jaha M J M, Alzahrani A M M, Alyamani A M M, Munshi A H A, Kalantan A A I, et al. Asthma: Overview on Diagnostic and Management approach in Primary Health Care. Arch. Pharm. Pract. 2022;13(1):114. https://doi.org/10.51847/DkIwXP7cnx 
developing countries with low rates and to developed countries with a high rate concerning migration [4]. There is no specific strategy, besides reducing maternal smoking, aimed at essential in asthma prevention among children or adults.

The predominant incidence of asthma is more frequent in boys rather than girls, among children; however, this reverses sometime during puberty because, in adults, prevalence is approximately $20 \%$ higher in women than men [5]. Indeed, compared to girls, boys have smaller airways in contrast with the lung size, which may explain the higher chance of asthma in young boys, but this phenomenon reverses during adolescence. A study focusing on 19-year-olds [6] individuals with asthma is indicated to be $21 \%$ at 7 years of age were in remission and $38 \%$ are with periodic asthma, and persistent asthma had $41 \%$. Boys were more probable to experience remission than girls as well as patients with acute asthma or sensitization to furred animals [6]. However, there remain general contributors such as hereditary and hormonal besides sex, such as obesity and cigarette smoking that are likely to increase the risk of asthma [7]. This disease causes an impaired quality of life, substantial disability, and deaths that could have been avoided in young adults and children alike even though asthma mortality has been dropping these past 25 years (mostly due to increased use of inhaled corticosteroids).

\section{Risk Factors}

Smoking is a well-known risk factor for asthma, endangering female smokers in particular. However, the prevalence of smokers in the general population is approximately the same as among asthmatics. Maintaining asthma control is more difficult with smokers than nonsmokers. The mechanisms behind adverse effects of smoking in bronchial asthma patients are corticosteroid insensitivity and altered airway inflammation [8].

Pollution is also a major factor, and exposure to outdoor and indoor air pollutants aggregate a massive threat for developing allergies and triggering its symptoms [9]. Obesity also has a significant impact on the risk of developing asthma as well as on its phenotype, and prognosis (as demonstrated by epidemiological studies). Health status is impaired in obese individuals with asthma, as these patients experience worse quality of life, more symptoms, an increased need for healthcare use, and higher severity of the disease [10]. Occupational risk factors (work environment) are another risk for asthmatic patients. Indeed, occupational asthma (OA) often goes unreported or undiagnosed and has been proven to lead to increased morbidity [11].

Current evidence also points to a causal link between asthma and chronic psychosocial stress, which findings suggest the difference in methylation and genes manifestation that control social, autonomic, immunologic, and neuroendocrine responses to stress as a probable reason. There is also evidence suggesting a possible genetic predisposition of chronically burdened youth to both allergies and posttraumatic stress disorder (PTSD) [12].

\section{Symptoms and Signs}

Symptoms of asthma are wheezing, coughing, tightness of the chest, tachycardia, tachypnea, and breathlessness. These symptoms appear in episodes of varying intensity. The symptoms may vary and usually correspond to exposures such as allergens, airway irritants, or respiratory infections. Exercise may bring out bronchoconstriction in some patients, which can result in asthma symptoms. Chronic symptoms can also appear at rest if the patient has uncontrolled asthma.

It must be noted that chest tightness is not often the only symptom, and cardiac disease should be suspected if that is the case [13]. Indeed, the presence of upper airway symptoms should be investigated, as they are thought to symbolize distinctive expressions of common allergic physiopathology: allergic rhinitis is a risk factor for incident asthma [14], and asthmatics often have concurrent sinusitis and rhinitis.

\section{Diagnosis}

Diagnosing asthma requires pulmonary function testing as well as a report on symptoms by the patient. It is important to exclude diseases that display similar symptoms to asthma, because frequently nonspecific symptoms of this disease and maybe through other disease precipitation processes, especially in older people who are likely to have other conditions.

The presence of comorbid or mimicking conditions must be assessed by physical examination, preferably a pulmonary examination. Expiratory wheezing is not specific for this condition but may be present and additional or alternate diagnoses will likely be suggested considering not being typical and inspiratory wheezing. Alternative diagnoses may be considered to crackles. Patients may have persistent postnasal drip or rhinitis, and examination of skin might disclose eczema. To conclude, it is necessary to evaluate for signs of heart failure and a cardiac examination should be performed. If asthma is a likely diagnosis after the evaluation and the patient's history, spirometry should be performed before and after the administration of the bronchodilator to evaluate expiratory airflow hindrance and variability in airflow predicament. Spirometry signifying both expiratory airflow hindrance and complete reverse of airflow hindrance resulting bronchodilator administration supports a diagnosis of bronchial asthma. However, one of asthma's key features is variability in symptoms and airflow limitation; oftentimes, spirometry is normal when asthma is well controlled. If that is the case but there remains clinical suspicion for asthma, it will be necessary to repeat spirometry at another time point in time. Indeed, to support the diagnosis of this disease, at least one episode of obstruction should be documented. A 
peak flow meter can be utilized to record the Variability of airflow constraint through constant testing (the patient records the best of 3 peak flows amid periods of respiratory symptoms or in the morning and the evening over 2 weeks). The diagnostic process of asthma does not require radiographic studies or blood tests unless an alternative diagnosis is suspected.

\section{Treatment}

Treatment costs and the economic burdens of the disease increment with unpleasant drug reactions. While the public health system has been working to enhance drug prevention and reduce episodes of unpleasant drug reactions, the problem continues to be pertinent; amid hospitalizations at the prompt hospital, unpleasant drug reactions still occur in $14-30 \%$ of patients, and $3-14 \%$ of patients have necessitated to extent their hospitalization because of these complications [15]. Disease control is improved with inhaled corticosteroids (ICS), which decrease asthma exaggerations [16]. Almost $50 \%$ of asthma exacerbations decrease through low-dose inhaled budesonide, in new-onset, untreated, constant asthma [17]. Pauwels et al. [18] furthermore, demonstrate high dose budesonide decreased chronic asthma exaggerations and the need for systemic corticosteroids continuation, through $50 \%$ in contrast to therapy with low-dose ICS in adults patients already taking mild doses of ICS but under poor control [18]. Conversely, as found by O'Byrne et al. [17], doubling the extent of safety was less than those patients who recently started ICS because the budesonide dose in poorly controlled patients on low-dose ICS decreased exaggeration rates by $30 \%$. This specifies that dose-response advantages with ICS are relatively flat [19]. In patients with a history of prior asthma exacerbations and poorly controlled asthma, the combination of long-acting beta-agonists such as budesonide and formoterol with ICS demonstrates a significant reduction of asthma exacerbations compared to patients treated with ICS alone [18]. Antileukotrienes have also proven to reduce exacerbations in adults and children [20]. Indeed, Montelukast (anti leukotriene) was useful in reducing asthma exacerbations to rhinovirus infections [20], but not for acute asthma attacks: in comparison with placebo, leukotriene modifiers/receptor antagonists diminished exaggeration rates by $41 \%$ but have been inferior to ICS.53. Tiotropium (an anticholinergic) additionally decreases the incidence of asthma exaggeration and may be prescribed for long period maintenance of chronic uncontrolled bronchial asthma in patients 6 years and older [21, 22].

The benefits of conservational control quota to prevent exaggeration are inadequate, likely because conservational intercessions tend to emphasize specific allergens.

\section{CONCLUSION}

Asthma is a lifelong condition that must be controlled. Episodes and inflammation are caused by triggers that will likely change over time. Common triggers include tobacco smoke, particulate pollution, allergens, changes in temperature, exercise, excitement, nonsteroidal inflammatory medicines, and upper or lower respiratory tract viral infections. Rhinovirus remains the most common trigger for asthma.

\section{ACKNOWLEDGMENTS: None CONFLICT OF INTEREST: None FINANCIAL SUPPORT: None ETHICS STATEMENT: None}

\section{REFERENCES}

1. Wu TD, Brigham EP, McCormack MC. Asthma in the primary care setting. Med Clin. 2019;103(3):435-52.

2. Vos T, Flaxman AD, Naghavi M, Lozano R, Michaud C, Ezzati M. A systematic analysis for the Global Burden of Disease Study 2010. Lancet. 2012;380(9859):2163-96.

3. To T, Stanojevic S, Moores G, Gershon AS, Bateman ED, Cruz AA, et al. Global asthma prevalence in adults: findings from the crosssectional world health survey. BMC Public Health. 2012;12(1):1-8.

4. Asher MI, Montefort S, Björkstén B, Lai CK, Strachan DP, Weiland SK, et al. Worldwide time trends in the prevalence of symptoms of asthma, allergic rhinoconjunctivitis, and eczema in childhood: ISAAC Phases One and Three repeat multicountry cross-sectional surveys. Lancet. 2006;368(9537):733-43.

5. Cabieses B, Uphoff E, Pinart M, Antó JM, Wright J. A systematic review on the development of asthma and allergic diseases in relation to international immigration: the leading role of the environment confirmed. PLoS One. 2014;9(8):e105347.

6. Leynaert B, Sunyer J, Garcia-Esteban R, Svanes C, Jarvis D, Cerveri I, et al. Gender differences in prevalence, diagnosis and incidence of allergic and non-allergic asthma: a population-based cohort. Thorax. 2012;67(7):625-31.

7. Andersson M, Hedman L, Bjerg A, Forsberg B, Lundbäck B, Rönmark E. Remission and persistence of asthma followed from 7 to 19 years of age. Pediatrics. 2013;132(2):e435-42.

8. Dixon AE. Rhinosinusitis and asthma: the missing link. Curr Opin Pulm Med. 2009;15(1):19-24.

9. Rabe KF, Adachi M, Lai CK, Soriano JB, Vermeire PA, Weiss KB, et al. Worldwide severity and control of asthma in children and adults: the global asthma insights and reality surveys. J Allergy Clin Immunol. 2004;114(1):40-7.

10. Jung KH, Hsu SI, Yan B, Moors K, Chillrud SN, Ross J, et al. Childhood exposure to fine particulate matter and black carbon and the development of new wheeze between ages 5 and 7 in an urban prospective cohort. Environ Int. 2012;45:44-50.

11. Weiss ST. Obesity: insight into the origins of asthma. Nat Immunol. 2005;6(6):537-9.

12. Sutherland ER, Goleva E, Strand M, Beuther DA, Leung DY. Body mass and glucocorticoid response in asthma. Am J Respir Crit Care Med. 2008;178(7):682-7

13. Ducharme FM, Sze MT, Chauhan B. Diagnosis, management, and prognosis of preschool wheeze. Lancet. 2014;383(9928):1593-604.

14. Shen H, Hua W, Wang P, Li W. A new phenotype of asthma: chest tightness as the sole presenting manifestation. Ann Allergy Asthma Immunol. 2013;111(3):226-7.

15. Kubaeva MB, Ivanov DA, Zyryanov SK. Optimization of clinical and pharmacological approaches to the treatment of patients with bronchial asthma. J Adv Pharm Educ Res. 2020;10(3):111-4.

16. Rosenberg SL, Miller GE, Brehm JM, Celedón JC. Stress and asthma: novel insights on genetic, epigenetic, and immunologic mechanisms. J Allergy Clin Immunol. 2014;134(5):1009-15.

17. Dahl R, Lundback B, Malo JL, Mazza JA, Nieminen MM, Saarelainen $\mathrm{P}$, et al. A dose-ranging study of fluticasone propionate in adult patients with moderate asthma. Chest. 1993;104(5):1352-8.

18. O'byrne PM, Barnes PJ, Rodriguez-Roisin R, Runnerstrom E, Sandstrom T, Svensson K, et al. Low dose inhaled budesonide and 
formoterol in mild persistent asthma: the OPTIMA randomized trial. Am J Respir Crit Care Med. 2001;164(8):1392-7.

19. Pauwels RA, Löfdahl CG, Postma DS, Tattersfield AE, O'Byrne P, Barnes PJ, et al. Effect of inhaled formoterol and budesonide on exacerbations of asthma. N Engl J Med. 1997;337(20):1405-11.

20. Busse WW, Chervinsky P, Condemi J, Lumry WR, Petty TL, Rennard $\mathrm{S}$, et al. Budesonide delivered by Turbuhaler is effective in a dose- dependent fashion when used in the treatment of adult patients with chronic asthma. J Allergy Clin Immunol. 1998;101(4):457-63.

21. Raghavan D, Jain R. Increasing awareness of sex differences in airway diseases. Respirology. 2016;21(3):449-59.

22. Johnston NW, Mandhane PJ, Dai J, Duncan JM, Greene JM, Lambert $\mathrm{K}$, et al. Attenuation of the September epidemic of asthma exacerbations in children: a randomized, controlled trial of montelukast added to usual therapy. Pediatrics 2007;120(3):e702-12. 